\title{
RESENHA
}

\section{O MURAL DO TEMPO: MANUAIS ESCOLARES EM PORTUGAL}

\author{
THE WALL OF THE TIME: TEXTBOOKS IN PORTUGAL \\ DOI: http://dx.doi.org/10.1590/2236-3459/49736
}

\author{
Rafaela Paiva Costa
}

Universidade Federal de Minas Gerais, Brasil.

\begin{abstract}
$\cos 80$
MAGALHÃES. Justino. O mural do tempo: manuais escolares em Portugal. Lisboa: Colibri/Instituto de Educação da Universidade de Lisboa, 2011.
\end{abstract}

Há pelo menos dois séculos os manuais assumem um importante papel no mercado editorial e na formação das mentalidades coletivas. Apesar disso, só a partir da década de 1960 e, sobretudo, já nos anos 1980, foi observado um interesse crescente pela história dos livros e das edições escolares em diferentes países, como Estados Unidos, Alemanha, Japão e França ${ }^{1}$. Em Portugal, Justino Magalhães tem desenvolvido estudos referenciais sobre cultura escrita, sistemas escolares e instituições educativas, no centro dos quais ele situa o livro escolar.

Professor catedrático da Faculdade de Psicologia e de Ciências da Educação da Universidade de Lisboa, Justino Magalhães é pesquisador da história da educação portuguesa, na linha de cultura escrita e modernidade educativa. Graduou-se em História, pela Universidade do Porto, e doutorou-se em Educação, pela Universidade de Minho. Realizou quatro pós-doutorados, os dois últimos na Universidade de Cambridge, no Reino Unido, e na École des Hautes Études en Sciences Sociales, na França. Já publicou vinte e quatro livros, mais de quarenta capítulos em livros, além de dezenas de artigos e

${ }^{1}$ Ver Choppin (2008, p. 9-12).

Hist. Educ. [Online]

Porto Alegre

v. 19

n. 46

Maio/ago., 2015

p. $261-266$ 
trabalhos em eventos científicos. O mural do tempo é a sua penúltima obra, publicada em novembro de 2011, pelas Edições Colibri e pelo Instituto de Educação da Universidade de Lisboa.

O livro é estruturado em duas partes: a primeira, O livro escolar na base da cultura escolar, tem dois capítulos: História do manual escolar e Livro escolar e razão educativa. A segunda, Manuais escolares em Portugal (sécs. XVI-XX), com três capítulos: Manuais do ensino primário elementar e complementar, Uma biblioteconomia em expansão e $O$ livro escolar no centro da convenção educativa. O livro se inicia com um pequeno texto intitulado $O$ mural do tempo, no qual o autor apresenta sua proposta e algumas premissas de análise.

Para finalizar a obra, retoma sua tese e principais argumentos no texto Memória do futuro: conservar, regimentar, prevenir. Trata-se de um ensaio cuja origem foi a análise da regulamentação do livro escolar. Nele, o autor parte da seguinte questão: "como o sistema punitivo da censura aos materiais impressos evoluiu para um sistema preventivo e de vigilância desde a produção até a circulação e ao uso?" (p. 264). Sua conclusão deu origem à tese de que disciplinar e censurar o livro escolar significou a normalização da leitura, a sistematização do conhecimento e a disciplinarização do pensamento, enquanto meios reguladores da sociedade. Isto se comprovaria pelo conjunto e pela hierarquia de órgãos e regulamentos que estruturaram os campos da autoria, edição, circulação e utilização dos livros escolares em Portugal, a partir de meados do século 19.

Nesse intuito, Magalhães apresenta um inventário de livros escolares publicados e adotados no ensino primário - elementar e complementar - português, do século 16 até início da década de 1970. São 1.043 títulos organizados em duas categorias: os livros escolares integrados, ou manuais escolares, e os livros escolares em sentido amplo, dispostos por matéria. Praticamente toda a segunda parte da obra é dedicada ao arrolamento deste conjunto de livros, comentado e comparado em suas categorias. Também se expõe e se analisa as listagens de manuais aprovados e adotados, publicadas entre 1882 e 1910.

A escolha metodológica foi a da abordagem serial ${ }^{2}$. Em trabalho anterior (Magalhães, 2006), o autor afirmou a legitimidade da abordagem específica da seriação no tratamento desse tipo material didático por meio da qual se faria emergir o que ele chamou de uma "etnohistoriografia do manual escolar" (p. 36). Aliás, a consideração do caráter complementar entre a história dele e a história do livro, em geral, justificaria esta escolha: principal suporte da cultura escolar, os manuais escolares constituem um caso particular no quadro mais amplo da cultura escrita.

Justino aponta que o reconhecimento da especificidade do manual escolar em relação ao livro originou um campo científico, a chamada manualística. Ela se ocupa do inventário de suas diversas tipologias, da recomposição de sua gênese e da evolução em

\footnotetext{
2 Justino faz referência aos trabalhos desenvolvidos por Alain Choppin na França, a partir da Rede Emanuelle, assim como o de Anne-Marie Chartier, e do espanhol Augustín Escolano Benito. Na América hispânica destaca a atuação da Rede Manes. No caso brasileiro, o autor cita o banco de dados de livros escolares do programa Livres, do Centro de Memória da Faculdade de Educação da Universidade de São Paulo, o projeto Memória de Leitura, ligado ao Instituto de Estudos da Linguagem da Universidade Estadual de Campinas, e o Livro didático e saber escolar 1810-1910, de Circe Bittencourt, publicado pela Editora Autêntica em 2008. Fornece, ainda, os endereços eletrônicos das bases e catálogos sobre manuais escolares destas e de outras iniciativas dentro do campo.
} 
sua configuração e semântica, peculiar aos estudos de seriação, e da hermenêutica das práticas pedagógicas, didáticas e culturais subjacente ao livro escolar. Empenha-se, ainda, em reconstituir seus circuitos e mecanismos de circulação e as formas de utilização, tomando o livro escolar como fonte histórica que consagra uma ordem de leitura.

Mesmo constituindo um objeto epistêmico e o centro de um campo particular, os manuais têm sido cada vez mais utilizados no corpus documental de pesquisas a respeito dos métodos e práticas escolares, como evidenciado no caso da produção em torno da história das disciplinas escolares. Ainda que a história do livro escolar não seja confundida com a sua utilização como fonte historiográfica, o autor informa, em outro trabalho (Magalhães, 2008), que essas investigações têm se cruzado. Sobre isso, ele inclui uma breve, mas importante observação: mesmo portador de normalização didáticopedagógica e de regulação política, o manual permanece sendo foco de estudos que privilegiam seus estatutos ideológicos.

No Brasil, até o início da década de 1990, grande parte dos trabalhos acadêmicos que tematizavam o livro escolar tendia a abordá-lo a partir da denúncia de seu caráter ideológico, como mencionaram Munakata e Bittencourt ${ }^{3}$. Análises mais circunstanciadas só foram impulsionadas com a entrada de discussões em torno do currículo, das disciplinas escolares, da cultura escolar, da história cultural, da história do livro e da leitura, referenciadas em Andre Chervel, Alain Choppin, Yvor Goodson e Roger Chartier. ${ }^{4}$

Justino Magalhães articula o manual no processo de composição do saber escolar:

Como transformação dos conteúdos, teorias e conceitos de uma matriz científica pura e ampla em matéria escolar, os manuais representam, sobretudo, uma adaptação científica, cognitiva e curricular, incorporada em distintos registros materiais e textuais, e são também uma forma de acesso às práticas de ler e dar a ler, pelo que constituem um contributo fundamental, senão único, para a história cultural. No interior da cultura escolar e da cultura escrita, a história do manual permite uma aproximação à ordem do conhecimento e às práticas pedagógicas, bem como a projecção e a inferência de distintas formas de aculturação e sociabilidade. (p. 20)

É possível questionar a maneira pela qual esta definição do lugar do manual escolar no processo de composição das disciplinas escolares se relaciona com a tese clássica de Chervel (1990), no que diz respeito à autonomia desse gênero de saber em relação às chamadas ciências de referência. De todo modo, o que Justino deixa evidente é que investigar a história do livro escolar passa por indagar a sua gênese, sua natureza, suas simbolizações e significações mais profundas com relação ao saber e ao conhecimento: a abordagem serial na longa duração visa a perscrutar a origem e a evolução dessa relação entre saber e conhecimento.

${ }^{3}$ Segundo Munakata (2012), esse tipo de abordagem caracterizou o livro escolar como "um simples conjunto de ideias e valores que deveriam ser condenados (ou aprovados) segundo certa ortodoxia" ( $p$. 183). Em outro trabalho recente, Bittencourt (2011) destaca que isso foi uma "tendência nas demais áreas da educação, inspiradas nas concepções de Althusser e Establet sobre o papel da escola no mundo capitalista" (p. 487).

${ }^{4}$ Um trabalho pioneiro no Brasil, que Munakata utiliza como referência desta renovação temática e historiográfica no campo da História da Educação, foi a tese de doutorado de Circe Bittencourt (1993). 
Segundo o autor, o estudo da regulação sobre o livro escolar ressalta os diferentes aspectos da racionalidade educativa subjacente e determinada por ele, visto que em todas as fases de sua materialidade, configuração e uso esteve presente um quadro educativo. Integrado na cultura escrita, o livro escolar incorporou uma orientação ideológica e comportou uma pragmática voltada para o progresso e construção do coletivo nacional que se tornou objeto de regulamentação, controle e censura em diversos âmbitos, como o cultural, o curricular e o didático-pedagógico.

O ideal de nação esclarecida, ordeira e hierárquica - que a partir do século 18 dirigiu o Estado no controle pela ordem moral, cívica e ética - orientou uma ação pedagógica baseada na censura prévia, preventiva, e posterior, ostensiva. O autor salienta que além dos normativos gerais em torno da circulação de ideias e dos domínios autoral e editorial, foram criados órgãos de fiscalização e, ao mesmo tempo, constituídos mecanismos e sistemas de controle e de punição. O manual escolar esteve sujeito não apenas aos condicionamentos de qualquer texto escrito, mas a preceitos especificamente escolares: seja pela definição prévia dos planos de estudo e das matérias a incluir em cada segmento de ensino e em cada disciplina, geralmente acompanhado de orientações metodológicas, seja pela promoção de concursos e produção de listagens de livros recomendados ou simplesmente autorizados ou excluídos.

Do estudo desta regulamentação e das listas de livros aprovados e adotados na virada do século 19 para o 20, Justino concluiu que o campo do livro escolar, isto é, de todos os materiais impressos não necessariamente elaborados para o espaço escolar mas assim empregados, foi muito mais amplo que o do compêndio e do manual. A normalização pedagógica e didática e a organização do currículo em uma hierarquia de ciclos escolares, conferiu mais consistência ao manual, incluindo a sua nacionalização fortalecida pela uniformização do livro. Ainda assim, manteve-se a tradição da diversidade bibliográfica e, em virtude da massificação escolar, as políticas relativas ao livro e à leitura sofreram mudanças.

Houve uma crescente preocupação com o rigor textual, nos aspectos de conteúdo e forma, bem como uma intensificação do livro enquanto suporte do texto escrito e da razão escolar. Ele também cumpriu a função de testemunho e memória sobre as matérias e os conhecimentos programados e ensinados, bem como se conformou em uma ferramenta de consulta para além da sala de aula. As bibliotecas escolares surgiram como destino para os compêndios e impressos afins, servindo à comprovação pedagógica e à exemplificação e normalização didática.

Para Justino, o livro estruturou o pensamento pedagógico, a ação didática, o conceito de escola, o método de transmissão e a apropriação do conhecimento. Essa aproximação entre o mundo do livro e o mundo escolar balizou e intensificou a prevenção, a advertência e a negociação entre as diversas partes envolvidas. Assim, autores, editores e leitores permaneciam previamente informados sobre a natureza dos objetos culturais, ideológicos e educacionais legitimados e autorizados, da mesma maneira que conheciam os campos de liberdade e os níveis e mecanismos de punição. Por outro lado, censores e avaliadores também tendiam a justificar suas decisões de modo a prevenir reclamações, mas igualmente a incorporar uma função pedagógica a seus pareceres. 
Dessa forma, a censura deu lugar a um regime de educabilidade, visto que o objeto cultural era investido de uma função educativa desde sua produção, como em sua recepção. A generalização e formalização desse processo implicaram que as matérias culturais se transformassem em currículos. Justino ainda aponta que, na medida em que foram correspondendo às necessidades, às prerrogativas e às circunstâncias históricas da cultura escolar e da pedagogia em geral, os diversos ramos do saber se estruturaram em disciplinas curriculares e a mesma operação envolveu o livro escolar.

Censurar e regularizar o livro, da configuração até a demarcação de matérias, passando pela orientação ideológica e as formas de uso e de acesso era, para o autor, assegurar uma normalização escolar e, consequentemente, prevenir e disciplinar os leitores. Em última instância, regular a sociedade. A liberdade de interpretação não é admitida, a priori e a posteriori, para o livro escolar. Suas variações de leitura são entendidas como incapacidade ou condicionalismo do leitor, ou ainda como atos perversos e ideológicos. É exatamente nesse aspecto que o manual escolar se distingue de outros livros, visto que apresenta orientações e ingerências explícitas em relação ao comportamento do leitor, instaurando uma ordem de leitura.

Finalmente, sendo memória da ação e da cultura escolar, o manual foi um instrumento do porvir. Comportou em si uma memória do futuro, prevenindo-o e normatizando-o, visto que foi um fomentador e organizador da mudança. As comissões de promoção de concursos, de aprovação e mesmo as comissões escolares de seleção desses livros agiam por antecipação. O livro foi adotado a partir do princípio de um amanhã desejado e projetado. Ele acolheu e deu forma a um ideário educativo; "reificou, deu configuração, ordem e significado à cultura escolar e fez da escolarização o caminho do futuro" (p. 265).

\section{Referências}

BITTENCOURT, Circe. Livro didático e conhecimento histórico: uma história do saber escolar. Tese (doutorado em História Social). São Paulo: USP, 1993. 369f. Faculdade de Filosofia, Letras e Ciências Humanas, Universidade de São Paulo.

BITTENCOURT, Circe. Produção didática de história: trajetórias de pesquisa. Revista de História, São Paulo, n. 164, 2011, p. 487-516.

CHERVEL, Andre. História das disciplinas escolares: reflexões sobre um campo de pesquisa. Teoria \& Educação, Porto Alegre, n. 2, 1990, p. 177-229.

CHOPPIN, Alain. Prefácio. In: BITTENCOURT, Circe. Livro didático e saber escolar (1810-1910). Belo Horizonte: Autêntica, 2008, p. 9-12.

MAGALHÃES, Justino. O manual escolar como fonte historiográfica. In: COSTA, Jorge Vale; FELGUEI-RAS, Margarida; CORREIA, Luís Grosso (coord.). Manuais escolares da biblioteca pública municipal do Porto. Porto: Faculdade de Psicologia e Ciências da Educação / Faculdade de Letras, 2008, p. 11-15.

MAGALHÃES, Justino. O manual escolar no quadro da história cultural: para uma historiografia do manual escolar em Portugal. Sísifo. Revista de Ciências da Educação. n. 1, 2006, p. 5-14.

MAGALHÃES. Justino. O mural do tempo: manuais escolares em Portugal. Lisboa: Colibri/Instituto de Educação da Universidade de Lisboa, 2011. 
MUNAKATA, Kazumi. O livro didático: alguns temas de pesquisa. Revista Brasileira de História da Educação. Campinas, v. 12, n. 3, 2012, p. 179-197.

RAFAELA PAIVA COSTA é estudante do curso de doutorado no Programa de PósGraduação em Educação da Universidade Federal de Minas Gerais. Bolsista da Capes.

Endereço: Rodovia BR316, Km 5, n. 5010, Residencial Ecoparque, Torre Ipê, apto. 98 - 67020-000 - Ananindeua - PA - Pará - Brasil.

E-mail: rafaelapaivacosta@yahoo.com.br.

Recebido em 20 de agosto de 2014.

Aceito em 25 de janeiro de 2015. 